\title{
IMPLEMENTATION OF VALUE MANAGEMENT AS AN ECONOMIC SUSTAINABILITY TOOL FOR BUILDING CONSTRUCTION IN NIGERIA
}

\author{
Ayodeji Emmanuel, Oke ${ }^{1}$, Douglas Omoregie, Aghimien ${ }^{1}$ and Samuel Olusola, \\ Olatunji ${ }^{1}$ \\ ${ }^{1}$ Department of Quantity Surveying, Federal University of Technology, Akure \\ P.M.B.704, Akure, Nigeria
}

\begin{abstract}
Today, several researches have been carried out in the area of sustainability with much emphasis being placed on the environmental dimension. Though this is good, a balance needs to be created between the environmental, economic and social sustainability dimensions. Bearing this in mind, the construction professionals are saddled with the responsibility of delivering sustainable construction projects using diverse tools. One of such tool is Value Management (VM). Hence, this research assessed the use of VM in delivering economically sustainable constructions. A case study approach was employed and the study revealed that VM has a great role to play in delivering economic sustainability in construction since both $V M$ and Sustainability (the economic dimension) have a common goal which is; achieving value for money. Notable benefits of VM in providing economic sustainability in construction includes: reduction of overall cost while maintaining function through identification and removal of unnecessary materials and process and use of local materials to save cost of importation and transportation. The study therefore recommends the implementation of VM in building construction and presentation at various workshops and seminars in order to enhance sustainable construction development through VM practise.
\end{abstract}

\section{KEYWORDS}

Construction projects, Cost, Nigeria, Sustainability, Value management

\section{INTRODUCTION}

The word sustainability is gradually becoming synonymous with the construction industry. According to Zhou, Keivani, and Kurul (2013), sustainability is complex in nature and it covers a wide range of topics from habitat conservation and energy consumption, to stakeholder satisfaction and financial results. Wood (2005) stated that sustainability is all things to all people and a web search on the definition of sustainability using Google found about 1,300,000 references. Today, the most widely accepted definition of sustainability is that given in the Brundtland Report" by World Commission on Environment and Development (1987). In the report, the idea of sustainability in construction is to provide construction projects that meet the needs of the present without compromising the ability of future generations to meet their own needs. Raynsford (2000) stated that a sustainable construction therefore aims to deliver built assets that enhances quality of life and offers customer satisfaction, provides flexibility and can cater for future changes in users needs, provides and supports desirable, natural and social environments; and maximise the efficient use of resources. Nazirah and Ijias (2006) stated that in providing a sustainable environment through construction, the decision makers must confront with social, economic and environmental issues throughout the project life. Bearing this in mind, 
exploring diverse ways of providing sustainable construction is necessary and one of such ways is the application of Value Management (VM).

The Office of Government Commerce (2007) defines VM as "a well established methodology for defining and maximising value for money", while Odeyinka (2006) defined VM as "a service, which maximises the functional value of a project through the management of its development from conception to completion and commissioning through the audit of all decisions against a value system determined by the client". From these definitions it therefore means that VM can be seen as a process directed towards analysing the functions of projects from its inception to completion and commissioning for the purpose of achieving best value for money and return on investment at lowest possible overall life cycle cost (Oke and Ogunsemi, 2013).

Beheiry (2006) observed that although considerable research has been and still being carried out in the area of sustainability, greater focus is generally placed on the environmental pillar. While the environmental dimension is important, more emphasis needs to be placed on the economic and social sustainability pillars in order to create a balance. This, according to Yeomans (2002) can be achieved through VM as it is the most robust mechanism to deliver a balance between the society, environment and economy. This was further corroborated by Nazirah and Ijias (2006) who stated that VM is a technique conducted to assist decision making, and holds a strategic position in incorporating sustainability issues into construction projects. It is in light of this that this paper assessed the use of VM as a tool for achieving economic sustainability in building construction in Nigeria, with the view of providing economically sustainable construction projects within the country.

\section{LITERATURE REVIEW}

\subsection{Overview of Sustainable Development in Construction}

According to Romiguer (2011), the emerging environmental movement of the 1960s which was concerned with human activities having severe and negative impacts on the planet, birth sustainable development. The report of Meadows, Randers and Behrens (1972) was one of the key works that highlighted this thinking while the Brundtland Report (1987) provided sustainable development as the solution to this problem. Since then, there has been various definitions aimed at describing sustainable development. One of such definitions is that of the forum for the future (2011) which defines sustainable development as a dynamic process which enables everyone to realise their potential and improve their quality of life in ways which simultaneously protect and enhance the Earth's life support systems. Awodele (2015) observed that sustainable development focuses on improving the quality of life for all of the earth's citizens without increasing the use of natural resources beyond the capacity of the environment to supply them indefinitely. Yekinni, Bello and Olaiya (2015) opined that sustainable development involves transforming natural resources into productive output and in the process creating a balance between economic progress and environmental conservation, given that both are imperative to our future survival.

Akbiyikli, Dikmen and Eaton (2009) stated that a sustainable construction can be seen as a path way through which the construction industry can move towards a sustainable development, bearing in mind the environmental, socio-economic and cultural pillars as observed by Chaharbaghi and Willis (1999) who opined that sustainable development is a concept based on a structure which stands on three pillars, namely economic, social and environmental. Thus, sustainability in construction can be said to be a way of trying to find a balance between economic, environmental and social factors in the design, construction, use and maintenance of buildings. 
As stated earlier, this research is focused on the economic dimension of sustainability, as this is an aspect mostly affected by VM practice while trying to achieve value for money.

\subsection{Economic Sustainability}

Romiguer (2011) stated that economic growth will always be the basis of human development. Hence, in recent years, sustainable products are of higher demand and this is growing much faster than the demand for conventional products. Thus, immense cost savings is being achieved through sustainable development and this happens to be one of the main objectives of sustainable development from the economic point of view (Agenda 21, 1992 as citied in Romiguer, 2011). Akadiri, Chinyio and Olomolaiye (2012), stated that economic sustainability has to do with maintenance of high and stable levels of local economic growth through improved project delivery, increased profitability and productivity.

A critical analysis of the case study carried out on the 'Enviro-Cottage'(Essays UK, 2013) shows certain important features for an economic sustainable structure. These include: use of design and the environmental- friendly products which will take future operating costs down to a minimum; use of durable and low maintenance materials for construction; installation of environmental features such as solar panels, water tanks etc that can end up increasing the value of the property; use of materials from local market, thereby optimising cost by reducing transportation expenses, efficient use of recycled, readily available and local building materials to save cost, use of design that minimise the need for future modifications to cater for occupants changing requirements which reduces long term cost. All these can be achieved through the use of VM as the incorporation of VM according to Oke and Ogunsemi (2011) will eliminate unnecessary design, reduce construction cost and enhance value for money.

\subsection{Value Management}

VM was developed in the United States during the 1940s and was first applied to construction projects in the 1960s, mainly by public sector bodies. It was born due to the shortage of products component which was an aftermath of the World War II. At this time alternative components were sort, but due to the war, these alternative components were often equally unavailable and this led to a search not for alternative components, but to a means of fulfilling the function of the component by an alternative method. It was later observed that this method produced low-cost products without reducing quality. After the war, the system was maintained as a means of both removing unnecessary cost from products and improving design hence birthing value engineering (as it was called at the time) process based on analysis of function (Palmer, Kelly and Male, 1996).

From an organization view, The Institute of Value Management (2008) defined VM as "a style of management particularly dedicated to motivating people, developing skills and promoting synergies and innovation, with the aim of maximizing the overall performance of an organization". The concept of VM according to The Society of American Value Engineers (2008) is defined as a systematic, multi-disciplinary effort directed towards analysing the functions of projects for the purpose of achieving the best value at the lowest overall life cycle cost. Thus, VM can be said to be a methodology use in identifying the function of a product, determining the value of the identified function and providing same at the lowest overall life cycle cost while achieving best value for money and return on investment.

VM employs the use of a VM workshop where selected stakeholders gather (Ellis, Wood and Keel, 2003) to brainstorm on the project with the aim of drawing up a cost effective design. The workshop follows the sequence of: information phase; speculation or creative phase; evaluation or judgement phase; development phase; and presentation phase. 


\subsubsection{Benefits of Value management}

Over the past few decades, the economy has changed rapidly and increasing competition has placed an importance and demand on increased efficiency, effectiveness and value for money (Rangelova and Traykova, 2014). VM addresses these three facets effectively and directly. The Institute of Value Management (2008) and The department of Housing and Works (2005) also observed that apart from acting as a cost reduction tool, the most visible benefits arising out of the application of VM include: better business decisions by providing decision makers a sound basis for their choice; enhanced competitiveness by facilitating technical and organizational innovation; a common value culture, thus enhancing every member's understanding of the organization's goals; improved products and services to external customers by clearly understanding, and giving due priority to their real needs; improved internal communication and common knowledge of the main success factors for the organization; simultaneously enhanced communication and efficiency by developing multidisciplinary and multitask teamwork; decisions which can be supported by the stakeholders; time savings through focus of effort; aid to the briefing and approvals process; enhancement of risk management measures; increased quality; improved sustainability; and promotion of innovative service delivery processes. These benefits according to Oke and Ogunsemi, (2011) are available to providers and consumers in all sectors of the society.

\subsubsection{Role of VM in Economic Sustainable Construction}

Following the Society of American Value Engineers (2008) definition of VM being a systematic, multi-disciplinary effort directed towards analysing the functions of projects for the purpose of achieving the best value at the lowest overall life cycle cost. The premise is that some unnecessary costs are inevitable in any building design; VM sets out to identify and eliminate these unnecessary costs, resulting in cost savings. VM should not be confused for cost control. $\mathrm{VM}$ focuses on value in relation to the function while cost control focus on cost of construction.

Noor, Kamruzzaman and Ghaffar (2015) observed that in Malaysia, VM has been recognized by the Government as a strategic planning tool and it has been practiced ever since as a suitable mechanism to deliver sustainable construction project. The application of VM during project development phase may be utilized to improve building sustainability. Hence the appropriate approach of sustainable development as a process will be able to balance and integrate social, economic and environmental sustainable values in construction.

In area of production, Yekinni et. al (2015) observed that there is a conceptual synergy between VM and Sustainable product and service design that leads to achieving best value in terms of quality and cost of a product/service. Thus, VM can be said to be a reliable tool in providing sustainable products.

In practice, at various stages of a VM workshop, the VM team try to analyse each function and seek better alternatives. Certain questions are asked and this includes questions like: What an element is? What does it do? What else can it do? What does it cost? What is its value? When these questions are answered, several alternatives are drawn and the best alternative is developed. In doing this, the VM team try to identify unnecessary cost which can be in; use of unnecessary components in the design, use of unnecessary materials which less expensive materials would have been able to replace and do the job satisfactorily or failure to identify opportunity cost.

This being the case, since cost savings is one of the major objectives of sustainable development from the economic point of view (Agenda 21, 1992, as citied in Romiguer, 2011), and VM sets out to achieve "value for money", it therefore follows that VM is the perfect mechanism for 
promoting the objective of an economic sustainable development. Hence VM plays an important role in the delivery of economic sustainable construction.

\section{RESEARCH METHODOLOGY}

In order to determine the role of $\mathrm{VM}$ in providing economic sustainability in a construction project and its perceived benefits, a case study research is appropriate (Yin, 2003). A case study was carried out on the 40 hours VM workshop set up for 4 different proposed projects in Ondo State, Nigeria. Facilitators and members of the team were trained on the history, basis and application of VM to construction works, prior to the examination of the projects. Each case study had professionals within the built environment as part of the VM team. The VM team during the course of the workshop identified certain elements that may benefit from the VM process and critically analysed these elements, proposing several alternatives and at the end picking the best suitable alternative.

\section{Case Study One}

Project type: A proposed viewing centre

Number of VM members: 6

Estimated cost: 2,013,385.00 Naira

The proposed structure can also be used as coaching centre or a centre for religious meetings or a community meeting hall in the future. At the end of the workshop, several modifications to the original were drawn up, with a view to achieve value for money without compromising function. Alternatives were drawn up and the best alternative in terms of function was chosen and recommendation made by the team. Main suggestions at the superstructure level includes: the use of wooden frame and plywood, $150 \mathrm{~mm}$ thick block, steel plate, $150 \mathrm{~mm}$ block half wall to be completed with plywood and the use of wooden frame and corrugated iron zinc for the masonry work as against the use of brick suggested in the original design. The use of corrugated iron roofing sheet, long span aluminium or stone coated aluminium roofing sheet on either a mono pitch, gable with reduced height of kingpost or hip roof was also suggested. The use of locally made batten door, flush door, wooden panel door, purpose made steel door, aluminium door, aluminium sliding window, aluminium casement window, projected aluminium window, purpose made steel window or louver window were suggested for both the door and window openings. Ceramic floor tiles, terrazzo floor finish, floor carpet, ordinary floor screed, or broken tiles were suggested for the floor, while cement and sand rendering, wall paper or Alucobond cladding were suggested for the walls. Asbestos board, celotex ceiling board, PVC ceiling sheet and plywood ceiling board as ceiling finishes were suggested while POP wall screed with emulsion paint, texcote or gloss paint is to be applied to screeded wall.

\section{Case Study Two}

Project type: A two (2) bedroom bungalow

Number of VM members: 5

Estimated cost: $8,193,890.25$ Naira

The proposed structure can also be used for public rent in the future. Main suggestions at the superstructure level includes: the use of $150 \mathrm{~mm}$ blocks for masonry work as oppose the $225 \mathrm{~mm}$ in the original design and the use of locally made wooden door or well fabricated local steel doors as against the imported doors in the initial design. Aluminium sliding windows with $5 \mathrm{~mm}$ thick tinted glass or louvers with aluminium frame was suggested for the window opening while $0.45 \mathrm{~mm}$ gauge long span aluminium roofing sheet, stone coated roofing sheet or corrugated iron 
roofing sheet and the use of wooden fascia or aluminium fascia were also suggested for the roof covering and fascia. The Team suggested the rendering of kitchen walls and painting of same with gloss or tiled up to door level. Removal of facing bricks in the window area and the use of POP, PVC, Asbestos or wooden ceiling finish were also suggested. For the floor finish, cement/sand screeding, vitrified tiles or Terrazzo were suggested as oppose the marble tiles in the original design, while all rendered walls are to be painted with either texcote or emulsion paint.

\section{Case Study Three}

Project type: Single bedroom en-suit security gate house

Number of VM members: 5

Estimated cost: 2, 869,752.61Naira

Notable suggestions at the superstructure level includes: the use of brick or $150 \mathrm{~mm}$ thick block as oppose the $225 \mathrm{~mm}$ block in the initial design. Locally made wooden panel or aluminium sliding door as oppose the imported doors and sliding window or louver blade window as oppose projected aluminium window in the original design. Wall tiles in the bathroom and kitchen are to be removed or the height reduced, while the bedroom should be screeded with cement/sand screed. Asbestos ceiling boards or PVC ceiling are to be used as oppose the POP in the initial design.

\section{Case Study Four}

Project type: A proposed church building

Number of VM members: 6

Estimated cost: 38,062,060.00 Naira

The proposed structure can also be used as an event centre in the future. Notable suggestions at the superstructure level includes: the use of $150 \mathrm{~mm}$ block in place of $225 \mathrm{~mm}$ block wall for masonry construction and corrugated iron sheet on wooden carcass, corrugated iron sheet on steel carcass or transparent rubber covering on wood carcass for roofing as oppose the stone coated roof covering on steel carcass initially designed. Locally made panel doors, security steel doors or sliding doors with burglar proof bars and louver blade window or aluminium casement window as oppose the purposed made security doors and glass projected window in the original design, were proposed. The use of ceramic tiles as oppose the terrazzo floor finish given in the original design was also suggested.

\section{FINDINGS AND DISCUSSIONS} 4.1 Findings from selected projects

At the end of the VM exercise, based on the experience of team members in building construction and obtaining best value for money, several modifications to the original design were drawn up, with a view of achieving value for money without compromising function. The best alternatives were chosen and recommendations made thereof. The economic sustainability features of these recommendations are pinpointed as this is the focal point of this research.

\section{Case Study One}

The VM team retained the use of brick in the original design due to its light weight and savings in finishes, gable roof with reduced kingpost height and long span aluminium roofing sheet due to its aesthetic and durability nature. The purpose made steel door and window in the original design 
were retained due to their durability and security function. Floor screed, cement/sand rendering to walls and PVC ceiling sheet were proposed for finishes. At the end of the exercise the VM team valued the project from an initial design cost of $\mathrm{N} 2,013,385.00$ to a reduced cost of $\mathrm{N} 1$, 452,100.00. This was achieved through a justified review of all elements and components associated with the proposed structure while maintaining its original function.

Thus, if the VM team recommendation is implemented, 28\% savings will be made. The use of bricks due to its light weight and aesthetic nature, long span aluminium roofing sheet, purpose made doors and PVC ceiling finish in the proposed building will go a long way in increasing the value of the structure should the owner decide to sell it in the nearest future.

\section{Case Study Two}

The VM team recommended the use of $150 \mathrm{~mm}$ block wall for masonry construction, locally made steel door externally with wooden panel doors internally and aluminium sliding windows. $0.45 \mathrm{~mm}$ gauge roof covering with aluminium fascia was recommended and this is because Ondo state has a stable wind which the aluminium fascia can withstand. Tiling of the kitchen and toilet walls up to door level was recommended, while all other walls are to be rendered. PVC was proposed in the sitting and dining rooms while asbestos ceiling finish was recommended in all other areas within the building. The use of vitrified floor tiles as floor finish, gloss paint for the upper part of the kitchen and toilet walls and emulsion paint for the remaining part of the building were proposed.

At the end of the exercise, the VM team valued the project from an initial design cost of $\mathrm{N} 8$, $193,890.25$ to $\mathrm{N} 5,121,167.63$. A whopping $38 \%$ savings will be made if the VM team recommendation is implemented and the use of well fabricated local steel door externally as oppose the imported metal door will go a long way in reducing the maintenance cost associated with doors within the building and also promote the use of local materials which will save cost of importation and transportation.

\section{Case Study Three}

The use of $150 \mathrm{~mm}$ block wall, wooden panel door and aluminium sliding window with burglar proof were recommended by the VM team. Tiling of the kitchen and toilet walls up to door level was proposed while the bedroom floor is to be screeded with cement/sand screed and PVC for ceiling finishing. At the end of the exercise the VM team valued the project from an initial design cost of $\mathrm{N} 2,869,752.61$ to a reduced cost of $\mathrm{N} 1,975,865.36$. Thus $31 \%$ savings will be made if the VM team recommendation is implemented.

\section{Case Study Four}

The VM team recommended the use of long span aluminium roof covering on wooden carcass for the roof of the proposed building, aluminium sliding windows and security steel doors for the windows and doors, vitrified floor tiles and PVC ceiling for both the floor and ceiling finishes. At the end of the exercise, there was a reduction in cost from the initial design cost of $\mathrm{N} 38$, $062,060.00$ to $\mathrm{N} 32,240,150.00$ leading to $15 \%$ savings.

The use of steel doors as oppose the aluminium sliding glass door in the initial design will go a long way in reducing maintenance cost associated with doors within the proposed building, while the use of vitrified floor tiles and PVC ceiling finishes as against the terrazzo and POP finishes in the initial design will save cost and still will not reduce the value of the building, thus achieving appreciable level of economic sustainability. 
Table 1: Cost and Percentage savings for each case study

\begin{tabular}{lcccc}
\hline & Initial Cost $(\mathrm{N})$ & Reduced Cost $(\mathrm{N})$ & Cost Variance $(\mathrm{N})$ & $(\%)$ \\
\hline Case Study 1 & $2,013,385.00$ & $1,452,100.00$ & $561,285.00$ & 28 \\
Case Study 2 & $8,193,890.25$ & $5,121,167.63$ & $3,072,722.62$ & 38 \\
Case Study 3 & $2,869,752.61$ & $1,975,865.36$ & $893,887.25$ & 31 \\
Case Study 4 & $38,062,060.00$ & $32,240,150.00$ & $5,821,910.00$ & 15 \\
\hline
\end{tabular}

\subsection{Discussion of Findings}

From the research, it is evident that though not stated, the main goal of VM is achieving economic sustainability within a proposed project. It was observed that VM identifies and removes unnecessary costs associated with the projects, hence leading to maximum cost saving of between $15-38 \%$ of the total estimated contract cost on all 4 case studies. Over specification is addressed and an improved building programme can be developed leading to quality time savings. This further corroborates Oke and Ogunsemi, (2011) findings that value management if fully incorporated will eliminate unnecessary design, reduce construction cost and enhance value for money which is the goal of sustainability.

The research further corroborates Nazirah and Ijias (2006) assertion that the potential of VM to assist the implementation of sustainability in the conceptual and design stage of a project is due to its utilisation of diverse knowledge resources, professional disciplines and stakeholders as various professionals with diverse backgrounds formed the VM team in each case study.

The research also corroborates Norton et. al, (1995) and Locke et.al (1994) observation that VM creates a clearer focus on the project objectives as the main purpose of the proposed project was kept in view all through the workshop and no alteration was done to the initial objective of the project. Also the research shows that VM works towards arriving at a more effective design, identification of alternative methods of construction and favourable adjustments to the construction timeline.

\section{CONCLUSION AND RECOMMENDATION}

Thus far, the research has been able to show that immense economic benefits abound with the use of VM. Huge economic sustainability can be achieved when a VM team is used on a project as participants have opportunities to ensure that construction projects create avenue for achieving value for money. However, in doing this, care must be taken not to create an imbalance between the three pillars of sustainability (environmental, economic and social).

From the evidence gathered, it is clear that VM plays an important role in delivering an economically sustainable project and it can be applied to any type of construction project (small, medium or large) as against the common belief that VM can only be effective when used on huge budget projects. The use of VM gives immense benefits as it identifies and eliminates areas of unnecessary designs which affects cost and has no functional benefits, reduce construction cost and time, and enhance value for money, thereby giving an overall satisfaction to the client.

The study therefore recommends VM as a truly beneficial tool in providing economic sustainability in any project and that it is worth investing some time and effort in by both the government and private investors. Presentation at various workshops and seminars in order to enhance sustainable construction development through VM practise should therefore be encouraged. 
The findings of the study also provide possible directions for further studies in that the researcher was able to review the economic sustainability of VM activities carried out on proposed projects. Further work can be done using ongoing or completed projects. Also, the use of VM in delivering sustainable construction in terms of environmental and social dimensions can be assessed.

\section{REFERENCES}

1. Akadiri, P. O, Chinyio, E. A and Olomolaiye, P. O (2012). Design of a Sustainable Building: A Conceptual Framework for Implementing Sustainability in the Building Sector. Buildings, Vol 2, pp 126-152

2. Akbiyikli, R., Dikmen S.U and Eaton D. (2009). Sustainability and the Turkish construction cluster: A general overview: Proceedings of the Construction and Building Research Conference of the Royal Institution of Chartered Surveyors, University of Cape Town, 10-11 September 2009

3. Awodele, O. A (2015). The Dynamics of Quantity Surveying Profession in the Context of Built Environment Sustainability. Being a Paper Presented at a day National Seminar Organised by The Nigerian Institute of Quantity Surveyors, Ekiti State Chapter, Ado-Ekiti, 22nd October.

4. Beheiry, S. (2006). Measuring Sustainability. The American University of Sharjah, Sharjah, UAE. Retrieved from www.scheller.gatech.edu/centers

5. Brundtland Report, (1987). "Our Common Future”, United NationsAssembly, Report of the World Commission on Environment and Development. Annex to General Assembly Document A/42/427.

6. Chaharbaghi, K. and Willis, R. (1999). Study and practice of sustainable development. Engineering Management Journal. Vol. 9 No.1 pp.41 - 48.

7. Ellis, R.C.T, Wood, G.D \& Keel, D.A. (2003). An Investigation into the Value Management Services Offered by UK Cost Consultants: Proceedings of the RICS Foundation Construction and Building Research Conference. School Of Engineering and the Built Environment University of Wolverhampton.

8. Essays, UK. (2013). Triple Bottom Lines and Sustainable Development Overview Construction Essay. Retrieved from http://www.ukessays.com/essays/construction/triple-bottom-lines-andsustainable-development-overview-construction-essay.php?cref $=1$ on $23^{\text {rd }}$ of June, 2015

9. Forum for the future (2011). Available at: http://www.forumforthefuture.org/whatis-sd (Accessed: 27 September, 2015).

10. Locke, M.B. (1994). Management of value in the British construction industry. SAVE International. London

11. Meadows, D. H., Meadows, D. L., Randers, J., and Behrens III, W. W. (1972). The Limits to Growth, Universe Books, New York.

12. Nazirah, Z. A., and Ijias, S. (2006). Involvement of Sustainability Issues in Value Management: Requisite Factors. ICCI

13. Noor, N. F, Kamruzzaman, S. N. and Ghaffar, N (2015), Sustainability concern in value management: A study on Governments building project. International Journal of Current Research and Academic Review; Special Issue-2 pp 72-83

14. Norton, B. R., and McElligott, W. C. (1995). Value management in construction, a practical guide. London. Macmillan Press Ltd

15. Odeyinka, H. A. (2006). The role of the quantity surveyor in value management. Paper presented at the 22nd Biennial conference/general meeting on Quantity surveying in the 21st Century Agenda for the Future. The Nigerian Institute of Quantity Surveyors.

16. Oke, A. E. and Ogunsemi, D. R. (2011). Value Management in the Nigerian Construction Industry: Militating factors and perceived benefits. Proceeding of the second international conference on advances in engineering and technology. Faculty of Technology, Makerere University, Uganda, 30 January - 1 February, 353-359

17. Oke, A.E. and Ogunsemi, D. R. (2013). Key Competencies of Value Managers in Lagos State, Nigeria: Proceedings of the West Africa Built Environment Research (WABER) Conference 2013 Accra, Ghana

18. Palmer, A., Kelly, J., and Male, S. (1996). Holistic appraisal of value engineering in construction in United States. Construction Engineering and Management, pp.324-326 
19. Rangelova, F. and Traykova, M. (2014). Value Management in Construction Project; First Scientific - Applied Conference with International Participation "Project Management in Construction"/Pmc/University Of Architecture, Civil Engineering and Geodesy.

20. Raynsford, N. (2000). Sustainable construction: the government's role, Proceedings of the Institution of Civil Engineers : Civil Engineering, 138(special issue 2), pp.16 - 22.

21. Romiguer, A. T., (2011). Sustainable Development: Objectives, Enablers and Challenges for Spanish Companies (Unpublished MSc Thesis), Tampere University of Technology.

22. Society of American Value Engineers (2008). What is value engineering? Retrieved September 27, 2015 from http://www.value-eng.org/

23. The Department of Housing and Works (2005). Value Management Guidelines, Government of Western Australia. Retrieved June 7, 2015 from http://www.utm.my/staff/value-management/

24. The Institute of Value management (2008). what is value management? Retrieved June 7, 2015 from http://www.ivm.org.uk/what_vm.htm

25. The Office of Government Commerce (2007). Value Management in Construction, London. Retrieved June 7, 2015, from http://www.ogc.gov.uk

26. Wood, B. (2005). 'Sustainable Building Strategy: Assessing Existing Building Stock'. The Queensland University of Technology Research Week International Conference, Brisbane, Australia, 4-8 July 2005

27. Yekinni A. A, Bello S. K and Olaiya K. A,(2015). Application of Value Engineering Techniques in Sustainable Product and Service Design. Science and Engineering Perspectives Vol. 10, pp $120-130$

28. Yeomans, P. (2002). Environmentally Sustainable Development Plus Value Management Equals Results Minus Rhetoric, Balancing the Scorecard, International Conference of the, Institute of Value Management, 29 - 30 August, Australia, Hobart, Tasmania.

29. Yin, R. K. (2003). Case Study Research: Design and Methods, Sage, Thousand Oaks, CA.

30. Zhou, L., Keivani, R., and Kurul, E.,(2013). Sustainability performance measurement framework for PFI projects in the UK. Journal of Financial Management of Property and Construction. Pp. $232-250$

\section{AUTHORS}

\section{Ayodeji Emmanuel, OKE}

Ayodeji Emmanuel, Oke bagged his B.Tech degree in Quantity Surveying from Federal University of Technology, Akure, Nigeria in 2006 with a first class (Hons.). He completed his M.Tech degree in Quantity Surveying in 2010 and recently bagged his $\mathrm{PhD}$ in the same profession in year 2015. To his name and in collaboration with academia within and outside Nigeria, he has authored more than 20 journals and 10 conference papers both locally and internationally. He has supervised more than 80 students at undergraduate and postgraduate level. He is a corporate member of Nigerian Institute of Quantity Surveyors, a registered Quantity Surveyor and a member of Nigerian Institute of Management. He is currently a Lecturer in Department of Quantity Surveying, Federal University of Technology, Akure, Nigeria.

\section{Douglas Omoregie, AGHIMIEN}

Douglas Omoregie, Agimien is a vibrant researcher and an observative writer with keen eyes for details and an intricate painter of the world with words. He bagged his B.Tech degree from the Department of Quantity Surveying, Federal University of Technology, Akure, Nigeria and he is currently pursuing a Masters of Technology degree in Quantity Surveying. He is currently a Teaching Assistant in Department of Quantity Surveying, Federal University of Technology, Akure, Nigeria.

\section{Samuel Olusola, OLATUNJI}

Samuel Olusola, Olatunji holds a HND and a PGD in Quantity Surveying and MSc in Construction Management. He is currently pursuing a PhD in Quantity Surveying. He is a corporate Member of Nigeria Institute of Quantity Surveyor, Registered Quantity Surveyor, and Member Society of Construction Industry Arbitrators. He is currently a Lecturer in Department of Quantity Surveying, Federal University of Technology, Akure, Nigeria
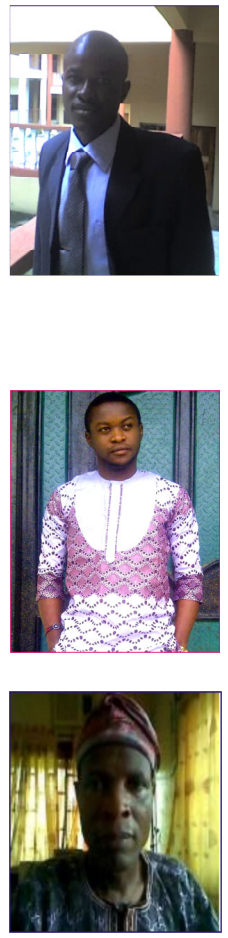